\title{
Complications of Stoma and The Management
}

\author{
Thamilselvam $\mathbf{P}^{*}$ \\ Department of surgery, National defence University of Malaysia, Malaysia
}

*Corresponding author: Thamilselvam P, Department of Surgery, National defence University of Malaysia, Malaysia

\begin{abstract}
A patient with stoma (colostomy or ileostomy) has poor quality of life and when he/she faced with stomal complications (Skin eczema, ischemia/necrosis, retraction, mucocutaneous separation, parastomal abscess, colostomy diarrhoea, parastomal hernia, obstruction, prolapse and retraction), the quality of life would go further down. So the people who are working in health system need to have more knowledge about the stoma and its complications. The definition of Quality of life is individuals' perception of their position in life in the contest of the culture and value system in which they live, in relation to their goals, expectations, standards and concerns affecting complex ways by the person's physical health, psychological state, level of independence, social relationships to salient features of their environment [1].The quality of life is very important problem for the patients with colostomy since they underwent surgery which made them to travel in the society with a new quality of life [2].
\end{abstract}

Keywords: Stoma; Quality of Life; Parastomal Hernia; Prolapse of Stoma; Colostomy and Ileostomy

\section{Introduction}

The stoma is the common surgical condition for general surgeons. The word "Stoma" comes from the Greek word meaning mouth or opening [3]. An intestinal stoma is an opening of the intestine on anterior abdominal wall made surgically [4]. Stomas are used to divert the fecal stream away from distal bowel in order to allow a distal anastomosis to heal as well as to relieve obstruction in emergencysituation. It may be temporary or permanent; depending on their role [5]. Though a lifesaving procedure, it may result in significant number of complications. Complications are divided into early complications (up to 30 days after operation) and late complications (more than 30 days after operation) [6,7]. Littre of Paris was the first to make a ventral colostomy in 1710 for a baby with imperforate anus [8]. Statically reported rates of complications of stomas vary widely in the literature [9]. Several reports focus solely on ileostomies or colostomies, making it even more difficult to make definitive conclusions about the overall incidence. Furthermore, conflicting data exists as to whether complication rates are equivalent with colostomies and ileostomies [10-12]. or are higher incidences with ileostomies [13]. Complication rates specific to loop ileostomies can be significant, ranging from $5.7 \%$ to $41 \%$ [14-16].and reoperation rates for loop ileostomies vary widely [16-19]. Complications of stoma rates obviously also vary depending on the circumstances surrounding stoma creation. Although it seems intuitive that emergency operations with gross peritoneal soiling, gangrenous or perforated intestine, and creation of stomas in debilitated or malnourished patients would be associated with increased postoperative morbidity, this has not been borne out in several studies [10-12] [20-22]. The very common complications of stoma creation include improper selection of site, vascular complications, retraction, peristomal skin irritation, peristomal infection/abscess/fistula, parastomal herniation, and postoperative bowel obstruction [9]. Each of these will be discussed individually

\section{Stoma Site Selection}

The proper selection of site is important and it hasto be done properly in preoperative period. In preoperative period, the surgeon and ET nurse haveto select the site and mark it by marker. It may not be possible in emergency explorative laparotomies due to shortage of time. The important factors are obesity and body habitus for proper siting. The umbilicus and Anterior superior iliac spine are the guiding landmarks and some time they may not useful in obese patients. Stomas placed near a prominent skin folds would complicate as leakage of gastro intestinal content in postoperative periods. In women, one must also consider pendulous breast tissue obscuring the stoma and interfering with management [23]. Ultimately, if the patient's lifestyle is compromised because 
of difficulties in obtaining a secure pouch due to improper siting, the treatment of choice is operative translocation with appropriate preoperative marking [7].

\section{Parastomal Infections}

Parastomal infections like abscess, fistulae are possible in early postoperative period. Peristomal abscesses are commonly seen in the setting of stoma revision or reconstruction of a stoma at the same site. These are mainly due to poor preparation skin in preoperative period and also be seen due to an infected hematoma and an infected suture site. Sometime the infection is due to stomal contents which may contain bacteria. In a patient with Crohn's disease, a peristomal fistula in conjunction with an ileostomy is almost invariably the result of recurrent Crohn's disease, as peristomal fistulae may occur in 7 to $10 \%$ of patients with an ileostomy in the setting of Crohn's disease [19,24,25]. The chemical, allergic, mechanical and infectious causes have been identified as causes. Most mechanical injuries occur from improper fitting or changing of an ostomy appliance. Repeated appliance changes may lead to mechanical stripping of skin epidermis. The denuded part of skin develops, typically in the distribution in contact with adhesives. The skin may be destroyed due to strong alkali and later it would invite infection. Early recognition of infection and treating the cause and the infection are more important to settle this issue.

\section{Parastomal Hernias}

Parastomal hernias are almost a type of incisional hernia located adjacent to stoma due to weakness muscles which are in the stoma and adjacent to stoma. Studies designed with very careful follow-up suggest that a paracolostomy hernia develops in more than $50 \%$ of patients followed for longer than 5 years. Most parastomal hernias occur in the first 2 years but can occur up to 10 years after stoma creation [26]. Surgical options for correcting a parastromal hernia are local primary repair, relocation, and repair with mesh. Local primary repair does not require a laparotomy and dissection can be minimal. The fascial defect around the stoma is strengthened by plication, and its technical ease is appealing. The results, however, are disappointing, with recurrence rates ranging from 46 to $100 \%$ [27]. Prophylactic synthetic mesh placement while performing stoma, would prevent these parastromal hernia. Laparoscopic parastomal hernia repair offers advantages of avoiding a large incision while providing a superior view of the hernia defect and facilitating wide intraperitoneal mesh placement [28].

\section{Necrosis of Stoma/Gangrene}

Usually it is more common in early postoperative period and associated with emergency surgeries. Poor vascularity and poor technique would be the causes. Recognition of stomal ischemia is important by observing colour in the operation theatre. Early revision in the operation theatre itself would settle the issues. Alternatively, a stoma with small areas of questionable ischemia found within days following creation may be observed expectantly.
Mucocutaneous separation may occur resulting in a small open wound that will usually heal by secondary intention if appropriate stoma care is employed. Poor vascular supply that does not cause acute complications may also lead to delayed complications, such as stomal stenosis and/or stricture [7]. Negligence of gangrene of stoma may lead to septicaemia which is high mortality condition.

\section{Retraction of Stoma}

The causes of stoma retraction are inadequate bowel mobilization, a heavy and bulky mesentery in the case of obesity. This may leads to adhesion of muco cutaneous which may leads to contamination of gastro intestinal content not only to skin but also to peritoneal cavity. The best method of avoiding these complications are adequate mobilization. Sothat the blood supply to the stoma segment of bowel would not be affected. Chronic stromal retraction may lead to stromal stenosis which may lead to intestinal obstruction as another complication. The treatment for stomal retraction is the revision of stoma by performing relaparotomy with creating an adequately sized fascial aperture to facilitate delivery of the stoma to the skin. The procedure includes the complete dissection of the colon from its lateral peritoneal attachments, mobilization of the splenic flexure, and scoring the medial aspect of the mesocolon and creating "relaxing incisions" [29]. Preforming new stoma site would be ideal solution to settle the issue of stoma retraction.

\section{Prolapsed Stoma}

Stomal prolapse is the protrusion of full thickness with all the layers of GI Tract (colostomy/ileostomy) through stomal orifice. The risk factors and the causes are poor abdominal muscle tone, weight gain/obesity, old age, increased intra-abdominal pressure like coughing, sneezing, pregnancy, increased fluid in the abdomen (ascites), poor surgical technique (such as a large opening in the abdominal wall, where the bowel was brought through to create the stoma at the time of surgery), and a colostomy that was brought out through the same laparotomy abdominal incision. It occurs commonly in loop colostomies when compared with end colostomies. The signs and symptoms of stoma prolapse are pain at stoma site, skin irritation due to poor maintenance of appliance. Sometimes it would lead to obstruction, incarceration, and strangulation another complications following stomal prolapse. The treatment in acute cases of stomal prolapse are reduction at the bedside with the help of ice for reduction of oedema of bowel wall and later surgical intervention as elective repair is needed. The meshes are sometime needed to strength the weakness of the musculature to prevent recurrences. Local Resection with linear cutting stapler can provide a unique and effective technique in addressing this issue when the stoma cannot be reversed. The first of this case was reported from Italy in 2003 where instead of linear stapler a circular stapler was used to transect the stoma and the patient did not develop any postoperative recurrence or complications [30]. 


\section{Electrolyte Imbalances with Dehydration}

It is more common in Ileostomies patients of early postoperative periods. Bowel mucosa is exposed to air and gets infected which leads to mucosal oedema and this impairs fluid absorption across the mucosal surface can lead to high volume output (colostomy diarrhoea). Hypokalaemia, hypomagnesemia, and hypocalcaemia are common findings and renal impairment is a reported complication [31,32]. Patients are to be monitored properly by repeated laboratory inventions. There may be signs and symptoms such as nausea, dizziness, malaise and fatigue. The treatment includes the rehydration and correcting the electrolyte imbalances by giving oral fluids and intravenous fluids proper electrolyte solutions.

\section{Conclusion}

Surgery of performing a stoma and it's postoperative complications are more common. These affect patients quality of life and sense of well-being while burdening the health care system. Very good care and meticulous attention to advanced technical detail should be executed to reduce the likelihood of postoperative complications and optimize stoma function. Reoperations for complications are required in 15 to $20 \%$ of patients with intestinal stomas [33]. emphasizing the impact of postoperative complications. It is critical for the surgeon to possess a thorough understanding of stoma complications and the treatment. This article provides an overview of the complications commonly seen in conjunction with the creation of intestinal stomas, focusing mainly causative factors, treatment options, and preventative suggestions.

\section{References}

1. Nishi C, A Patwardhan The Quality of Life 6th MCC abstract Symposium2 quality of life 6 th Malaysian colorectal conference $\& 5^{\text {th }}$ congress of the Asian society of stoma rehabilitation 6/55

2. Thamilselvam P, Khairuzi S (2003) Quality of life after colostomy. Reviews of Progress International Weekly Medical Research Journal 1(19).

3. Taylor P (2005) An introduction to stomas: reasons for their formation. Nurs Times 101(29): 63-64.

4. Irving MH, Hulme O (1992) Intestinal stomas. Br Med J 304: 1679-1681.

5. Saunders RN, Hemingway D (2005) Intestinal Stomas. Surg Int 71: 4447.

6. Ahmad Z, Apoorv S A (2013) clinical study of intestinal stomas: its indications and complications. International Journal of Research in Medical Sciences 1(4):536-540.

7. Kann B R (2008) Early stomal Complications. Clin Colon Rectal Surg 21(1): $23-30$

8. Khalid AM, Irshad W (1991) Surgical history of intestinal obstruction Specialist 8 (1): 55-60.

9. Kann B R, Cataldo T C (2008) Early stomal complication. Clin Colon Rectal Surg 21(1): 23-30.

10. Leenan L PH, Kuypers J HC (1989) Some factors influencing the outcome of stoma surgery. Dis Colon Rectum 32(6): 500-504
11. Duchesne J C, Wang Y, Weintraub S L, Boyle M, Hunt J P (2002) Stoma complications: a multivariate analysis. Am Surg 68 (11): 961-966.

12. Robertson I, Leung E, Hughes D (2005) Prospective analysis of stomarelated complications. Colorectal Dis 7(3): 279-285.

13. Park J, Del Pino A, Orsay CP (1999) Stoma complications: the Cook County Hospital experience. Dis Colon Rectum 42(12): 1575-1580.

14. OToole GC, Hyland J MP, Grant D C, Barry MK (1999) Defunctioning loop ileostomy: A prospective audit. J Am Coll Surg 188(1): 6-9.

15. Winslet MC, Barsoum G, Pringle W (1991) Loop ileostomy after ileal pouch anastamosis-is it necessary? Dis Colon Rectum 34(3): 267-270.

16. Gooszen AW, Geelkerken RH, Herman J (1998) Temporary decompression after colorectal surgery: randomized comparison of loop ileostomy and loop colostomy. Br J Surg 85(1): 76-79.

17. Senapati A, Nicholls RJ, Ritchie JK (1993) Temporary loop ileostomy for restorative proctocolectomy. Br J Surg 8(5): 628-630.

18. Wexner SD, Taramow DA (1993) Loop ileostomy is a safe option for temporary fecal diversion. Dis Colon Rectum 36: 349-354.

19. Carlsen E, Bergen AB (1999) Loop ileostomy: technical aspects and complications. Eur J Surg 165(2): 140-143.

20. Porter JA, Salvati EP, Rubin RJ, Eisenstat TE (1989) Complications of colostomies. Dis Colon Rectum 32(4): 299-303.

21. Mahjoubi B, Moghimi A, Mirzaei R, Bijari A (2005) Evaluation of the end colostomy complications and the risk factors influencing them in Iranian patients. Colorectal Dis 7(6): 582-588.

22. Mealy K, Broin EO, Donohue J, Tanner A, Keane FB (1996) Reversible colostomy - what is the outcome? Dis Colon Rectum 39(11): 1227-1231.

23. American Society of Colon and Rectal Surgeons Committee Members, Wound Ostomy Continence Nurses Society Committee Members (2007) ASCRS and WOCN joint position statement on the value of preoperative stoma marking for patients undergoing fecal ostomy surgery. J Wound Ostomy Continence Nurs 34(6): 627-628.

24. Leong A PK, Londono Schimmer EE, Phillips R KS (1994) Life table analysis of stomal complications following ileostomy. Br J Surg 81(5): 727-729.

25. Greenstein AJ, Dicker A, Meyers S, Aufses AH (1983) Peri-ileostomy fistulae in Crohn's disease. Ann Surg 197(2): 179-182.

26. Londono Schimmer EE, Leong A P, Phillips R K (1994) Life table analysis of stomal complications following colostomy. Dis Colon Rectum 37(9): 916-920.

27. Williams J G, Etherington R, Hayward M W, Hughes L E (1990) Paraileostomy hernia: a clinical and radiological study. Br J Surg 77(12): 1355-1357.

28. Shah NR, Craft RO, Harold KL (2013) Parastomal hernia repair. Surg Clin North Am 93(5): 1185-1198.

29. Cataldo PA (2008) Technical tips for stoma creation in the challenging patient. Clin Colon Rectal Surg 21(1): 17-22.

30. Trentin G, De Simone P, Mainente P, Agresta F, Bedin N (2003) Repair of mucosa stomal prolapse with circular stapler. Technical note. Chirurgia italiana 55(1): 141-143.

31. Klink CD, Lioupis K, Binnebösel M (2011) Diversion stoma after colorectal surgery: loop colostomy or ileostomy? Int J Colorectal Dis 26(4): 431-436.

32. Baker ML, Williams R N, Nightingale J M (2011) Causes and management of a high-output stoma. Colorectal Dis 13(2): 191-197.

33. Shellito PC (1998) Complications of abdominal stoma surgery. Dis Colon Rectum 41(12): 1562-1572. 
(C) (P) This work is licensed under Creative

To Submit Your Article Click Here: Submit Article

DOI: $10.32474 /$ SCSOAJ.2019.02.000132

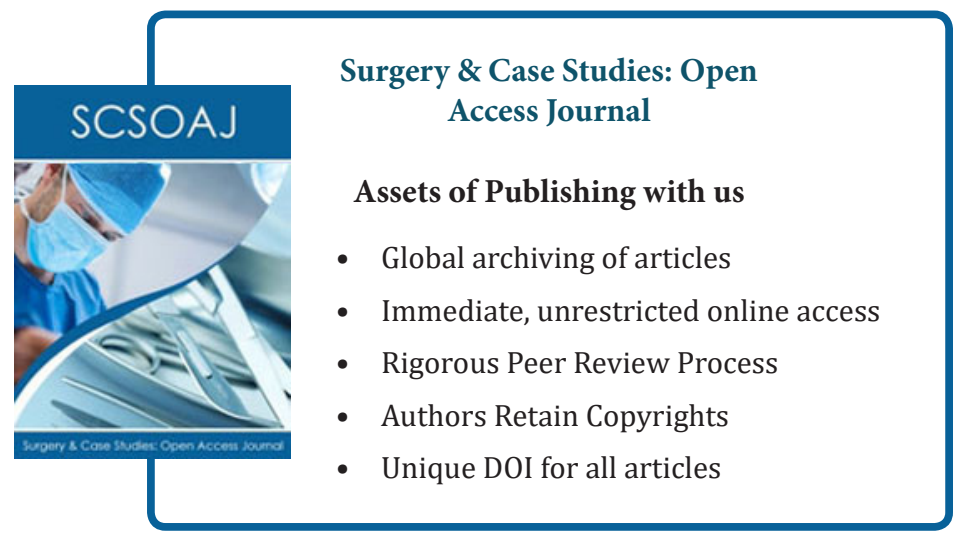

